\title{
Medical service utilization and out-of- pocket spending among near-poor National Health Insurance members in South Korea
}

Sooyeol Park ${ }^{1,2}$

\begin{abstract}
Background: The public health care system in South Korea is a two-tiered system. The lowest-income population is covered by the Medical Aid program, and the remaining population is covered by the National Health Insurance. The near poor, a relatively low-income population which is excluded from South Korea's Medical Aid program due to exceeding the income threshold, experiences insufficient use of medical services and incurs high out-of-pocket expenses due to a lack of coverage under the country's National Health Insurance (NHI) program. This study aims to examine medical utilization, out-of-pocket spending, and the occurrence of catastrophic health expenditures among the near-poor group compared to both Medical Aid beneficiaries and other (higher income) NHI members.

Methods: A cross-sectional study was conducted drawing upon a nationally representative dataset derived from the 2018 Korea Welfare Panel Study. The study classified people into three groups: Medical Aid beneficiaries; the near-poor population below $50 \%$ of the median income threshold but still not qualifying for Medical Aid and thus enrolled in $\mathrm{NHI}$; and $\mathrm{NHI}$ members above the threshold of $50 \%$ of the median income. Using a generalized boosted model to estimate the propensity score weights between study groups, this study examined medical utilization, out-of-pocket spending, and the occurrence of catastrophic health expenditure among the study groups.

Results: The findings suggest that the utilization of medical services was not significantly different among the study groups. However, out-of-pocket spending and the occurrence of catastrophic health expenditure were significantly higher in the near-poor group compared to the other two groups.

Conclusions: The study found that the near-poor group was the most vulnerable among the Korean population because of their higher chance of incurring greater out-of-pocket spending and catastrophic health expenditures than is the case among the Medical Aid beneficiary and above-poverty line groups. Health policy needs to take the vulnerability of this near-poor population into account.
\end{abstract}

Keywords: Medical utilization, Out-of-pocket spending, Catastrophic health expenditure, Poverty, Relative poverty

Correspondence: spark229@jhu.edu

'Division of Health Care Management and Policy, Department of Public

Health Sciences, Graduate School of Public Health, Seoul National University,

Seoul 08826, Republic of Korea

2Department of Health Policy and Management, Johns Hopkins Bloomberg

School of Public Health, 615 N. Wolfe Street, Baltimore, MD 21218, USA

C C The Author(s). 2021 Open Access This article is licensed under a Creative Commons Attribution 4.0 International License, which permits use, sharing, adaptation, distribution and reproduction in any medium or format, as long as you give appropriate credit to the original author(s) and the source, provide a link to the Creative Commons licence, and indicate if changes were made. The images or other third party material in this article are included in the article's Creative Commons licence, unless indicated otherwise in a credit line to the material. If material is not included in the article's Creative Commons licence and your intended use is not permitted by statutory regulation or exceeds the permitted use, you will need to obtain permission directly from the copyright holder. To view a copy of this licence, visit http://creativecommons.org/licenses/by/4.0/ The Creative Commons Public Domain Dedication waiver (http://creativecommons.org/publicdomain/zero/1.0/) applies to the data made available in this article, unless otherwise stated in a credit line to the data. 


\section{Background}

Universal health coverage is intended to allow access to essential health services while providing financial protection from catastrophic health expenditures and subsequent impoverishment due to health care expenses [1]. The public health care system in South Korea is a twotiered system composed of two programs aimed at providing protection from catastrophic health expenditure and ensuring access to essential health services: National Health Insurance (NHI) and the Medical Aid program. The entire population is covered by one of these two programs. NHI is operated in the form of social insurance with contributions from its members. Medical Aid is a public aid program that guarantees access to needed health services to low-income populations in need of medical assistance. It is comparable to the Medicaid program in the US.

The utilization of medical services is influenced by various factors. Previous studies have indicated that medical service utilization is influenced not only by health status but also by demographic and socioeconomic factors such as age, gender, marital status, education, the particulars of the health care system, and quality of life [2, 3]. Although these factors differ between NHI members and Medical aid beneficiaries [4], Medical Aid beneficiaries suffer greater economic difficulties, higher unemployment, a higher prevalence of chronic disease, and more advanced age compared to NHI members [5]. Due to insufficient ability to care for themselves, Medical Aid beneficiaries face barriers in consuming efficient medical services compared to NHI members [6]. The differences in medical service usage among Medical Aid beneficiaries and NHI members are considered to be closely related to demographic and socioeconomic health-related factors since Medical Aid beneficiaries tend to have higher needs for medical service than health insurance subscribers.

Although, because of strict criteria in the Medical Aid program and the obligatory provider rule, Medical Aid is not covering enough people who are in need of Medical Aid benefits because of their socioeconomic situation. South Korea's relative poverty rate based on a threshold of below $50 \%$ of national median income was $17.5 \%$ in 2017 , but only $3 \%$ of the total population was eligible for Medical Aid in that year [7]. Also, those who meet the income threshold but are excluded from Medical Aid because of the existence of an obligatory provider was estimated at 930,000 in 2015, which accounts for $1.82 \%$ of the total population in that year and equals $56.36 \%$ of the total Medical Aid beneficiaries (1.65 million) in that year [8].

The near-poor are defined under the National Basic Living Security Act as those who are ineligible for public aid programs but who have equivalized disposable household incomes less than $50 \%$ of median household income [9]. The OECD also defines relative poverty as such [10]. The near-poor in South Korea show similar sociodemographic characteristics as Medical Aid beneficiaries, although one study found that the poor not enrolled in Medical Aid included a higher proportion of the elderly and those with less education [11]. Due to these similar characteristics, the near-poor share with Medical Aid beneficiaries, they demonstrate greater medical needs but are experiencing lower medical service utilization and higher levels of unmet needs compared to Medical Aid beneficiaries and non-poor NHI members.

This excluded group is enlisted in NHI. Combined with NHI's insufficient coverage, the majority of the low-income population remains in a blind spot within the health care system. With the low coverage provided by South Korea's health insurance, high out-of-pocket spending is blamed for the occurrence of unmet needs among the near-poor caught in this blind spot in the health care system [5]. Excessive out-of-pocket spending caused by the low coverage of NHI makes patients with few financial resources vulnerable to catastrophic health expenditures and subsequent impoverishment. Because of this under-insuring taking place within NHI, it cannot function properly as a primary component of the social safety net protecting citizens from financial crises caused by illness $[12,13]$.

The characteristics shared by the near-poor with Medical Aid beneficiaries means that the near-poor population tends to experience greater medical needs than the non-poor population. Because they cannot benefit from Medical Aid and are enrolled in NHI, which is criticized for low coverage, the near-poor have a higher chance of facing excessive medical costs and unmet needs. Due to this distinctive characteristic of near-poor NHI members that affect medical utilization, there is a need to distinguish the near-poor population from other NHI members and compare them to each other and to Medical Aid beneficiaries in order to examine the different sociodemographic and policy contexts they inhabit.

Extensive research has been performed on health care utilization and out-of-pocket spending among lowincome populations in South Korea. The studies reviewed here indicate that Medical Aid beneficiaries tend to use more medical services but experience less out-of-pocket spending compared to NHI members [14, 15]. However, studies examining health utilization and out-of-pocket spending among the near-poor are limited. Choi (2015) [16] found that poor people not enrolled in Medical Aid had significantly lower medical utilization compared to Medical Aid beneficiaries, and greater healthcare costs as well. However, these studies have only compared the near-poor with Medical Aid 
beneficiaries and do not include the population above the threshold of $50 \%$ of median income, or else they did not divide the low-income groups according to specific criteria to separate the near-poor out of the low-income population. Studies on the effects of the US Medicaid program among the poor and near-poor showed that the expansion of US Medicaid substantially increased the use of healthcare services, which indicates the possibility of unmet needs among the uninsured near-poor population in the US [17-20].

\section{Establishment and recent policy changes in the health care system in South Korea}

The NHI began in 1977 by covering workers in large corporations. It continuously expanded its coverage to other groups, achieving universal medical coverage after only 12 years [21]. The original form of the Medical Aid program was initiated in 1997 as a part of the South Korean social welfare program and re-envisioned as the Medical Aid program in 2001. The entitlement criterion for Medical Aid is earning less than $40 \%$ of median income. However, if an obligatory provider exists and the obligatory provider's income exceeds the sum of the median value of the national household income for obligatory providers, and $40 \%$ of the beneficiary's, the person in question is excluded from Medical Aid enrollment, even if the person's obligatory provider fails to provide support [7]. Medical Aid beneficiaries are classified as Type I and Type II recipients based on their level of inability to work or incapacitation [22]. Type I beneficiaries are exempted from out-of-pocket payments for any medical utilization covered by the health care system. Type II beneficiaries are required to pay a minimum coinsurance of up to $15 \%$ [1]. Coinsurance for NHI members differs according to the health service and type of hospital involved. For inpatient services, the coinsurance rate is generally up to $20 \%$. Outpatient services vary with the type of hospital: For clinics, the coinsurance rate is $30 \%$; hospitals, $40 \%$; general hospitals, $50 \%$; and for tertiary hospitals, up to $60 \%$ of the fee [23].

Although South Korea achieved a degree of universal health care with the expansion of NHI in 1989, the regime has been criticized for insufficient benefit coverage. For example, computed tomography was not covered until 1995, magnetic resonance imaging was excluded from the benefits until 2005, and overall coverage reached only $62.7 \%$ in 2017, below the Organization for Economic Cooperation and Development average of $73 \%$ [24].

The South Korean government implemented several policies to increase the coverage of the health insurance system and lessen the burden of health expenditures. A catastrophic health expenditure support program for the population earning below $100 \%$ of the national median income was launched for four major conditions (cancer, cardiovascular and cerebrovascular disease, and rare diseases) in 2013 to control catastrophic medical costs and the occurrence of unmet needs due to high health expenditures in low-income populations [25]. In 2018, this was expanded to cover all inpatient and outpatient services for cancer, cerebrovascular disease, heart disease, rare diseases, severe incurable diseases, and severe burns. Recipients became able to receive up to 20 million won (approximately $\$ 18,000$ ) annually for out-of-pocket and uncovered service fees [25]. NHI coverage was extended in 2017 to include coverage for all necessary medical services and control future and existing uncovered services, lower the cost-sharing limit, and prevent catastrophic medical costs [26]. There are several government support programs for the near-poor, but most of these programs are offered in the education and housing sectors. In the health sector, a support program for out-of-pocket spending exists for households below $50 \%$ of the national median income, but the program is limited to chronic diseases only [27].

\section{Aims}

Therefore, this current study aims to examine medical service utilization and out-of-pocket medical spending in near-poor populations by assessing the differences between medical aid beneficiaries and non-poor NHI members. This study analyzes general characteristics by dividing total respondents according to the equivalized disposable household income of $50 \%$ of median income. It then separates the near-poor population from the low-income population according to specific criteria which will be discussed later. In addition, it analyzed medical utilization and out-of-pocket spending and the chance of experiencing catastrophic health expenditure among three separate groups.

\section{Methods \\ Data source}

Data were used from the 14th Korea Welfare Panel Study (2019) database, which was conducted by Seoul National University and the Korea Institute for Health and Social Affairs from February 18 through May 21, 2019. The Korea Welfare Panel Study was designed to provide a probability sample of South Korea's population. The period of the survey was January 1 through December 31, 2018 for flow variables and December 31, 2018 for stock variables.

Among the total of 14,418 individuals from the 14th Korean Welfare Panel Study data, 3,183 individuals were excluded due to being a minor under the age of 18 , missing health care program type information, being beneficiaries of free medical treatment for reasons of national merit, and/or as individuals above the poverty line 
but still beneficiaries of Medical Aid. Finally, 11,235 individuals were selected as subjects of this study.

\section{Variable definition Defining the Study Group}

The study population was categorized into three groups: Medical Aid beneficiaries, the near-poor, and those above the poverty line. The relative poverty line was defined as $50 \%$ of median income by the number of household members in 2018. Near-poor was defined as the population who are below the relative poverty line and enrolled in NHI, those who were subject to National Basic Living Security Aid in 2018 but not enlisted in Medical Aid because an obligatory provider's income exceeded criteria, or those who were unable to pay the $\mathrm{NHI}$ contribution for more than six months and triggered exclusion from NHI benefits. NHI members not classified as near-poor were placed in the above-povertyline group. The entire population enlisted as Medical Aid beneficiaries were grouped as Medical Aid beneficiaries.

\section{Selection and definition of explanatory variables}

This study examined two types of medical utilization for 2018: outpatient services and inpatient services. Inpatient services were examined in terms of three variables: hospital visits, hospitalized days, and hospitalized days per visit. For out-of-pocket spending, the Korea Welfare Panel Study includes all out-of-pocket spending, including hospital costs, dental costs, traditional Korean medicine costs, and drug costs. Catastrophic health expenditures are defined as annual out-of-pocket spending exceeding a specified fraction of annual income, which is distinct from high health costs defined simply as those exceeding a predetermined amount [28]. The specified fraction threshold varies between 10 and $40 \%$ : for this study, $10 \%, 20 \%, 30 \%$, and $40 \%$ were used as thresholds.

Sociodemographic, health-related, and private insurance-related variables were set as predisposing factors affecting medical utilization and medical spending and included as covariates in regression. For sociodemographic variables, sex, marital status, education status (no completion, below high school diploma, high school diploma, above high school diploma), occupation status (temporary employee, employer, self-employed, unpaid family worker, unemployed or economically inactive, permanent employee), age, and monthly equivalized disposable household income were included. Income was defined as equivalized disposable personal income by dividing household disposable income by the square root of the number of household members to account for differences in household size. For health-related variables, self-perceived health status (healthy, unhealthy), chronic disease states (whether the respondent has at least one chronic disease), depression state, and disorder states were included. Depression state was measured on the CESD-11 scale. Depression status was defined as the sum of CESD-11 questionaries (0-33 points) multiplied by $20 / 11$ being greater than or equal to 16 [29]. Respondents were grouped as having a disorder if any type of mental, kidney, heart, respiratory, liver, physical, speech, facial nerve, brain lesion, visual disturbance, hearing impairment, mental retardation, or intestinal disorder was present. For private insurance-related variables, private insurance subscription status (whether the respondent has at least one type of private insurance) was included.

\section{Statistical analyses}

This study examined the associations of Medical Aid and poverty on health utilization, out-of-pocket spending, and the occurrence of catastrophic health expenditures. Because the decision to use medical services and incur out-of-pocket spending is not random given that an individual's health status, occupational status, and various other factors influence it, the study applied the model by Rubin (1974) [30]. Most studies use propensity scores to control for two groups, but this study included three groups of interest. To estimate robust propensity scores for three groups with more balance properties, this study applied McCaffrey (2013) 's model which uses a machine-learning-driven generalized boosted model (GBM) to estimate propensity score weights among multiple treatment groups [31]. To perform a GBMestimated propensity score weighting, this study applied Cafalu (2017) 's method on the twang package in R run on STATA [32]. Additional information on estimating propensity scores for multiple treatments can be found in McCaffrey (2013) and Cafalu (2017) [31, 32]. Using prior knowledge to include covariates that affect the outcome variable [33], from the predisposing factors mentioned above, this study included sex, age, marital status, education, employment status, income, and private insurance coverage status as covariates to estimate the propensity score. Self-reported health status, chronic disease states, depression states, and disorder states were excluded because there is a chance that the healthrelated variables might bias the propensity score and lead to bias in the estimated treatment effects.

After running the package, the assessment of the weights was checked to make sure that the models were optimized in the balance statistics of interest. It was observed that the balance measures were optimized within 15,000 iterations. The study then compared absolute standardized differences among the included covariates to estimate the propensity score weight (Fig. 1). After propensity score weights were applied, all absolute 


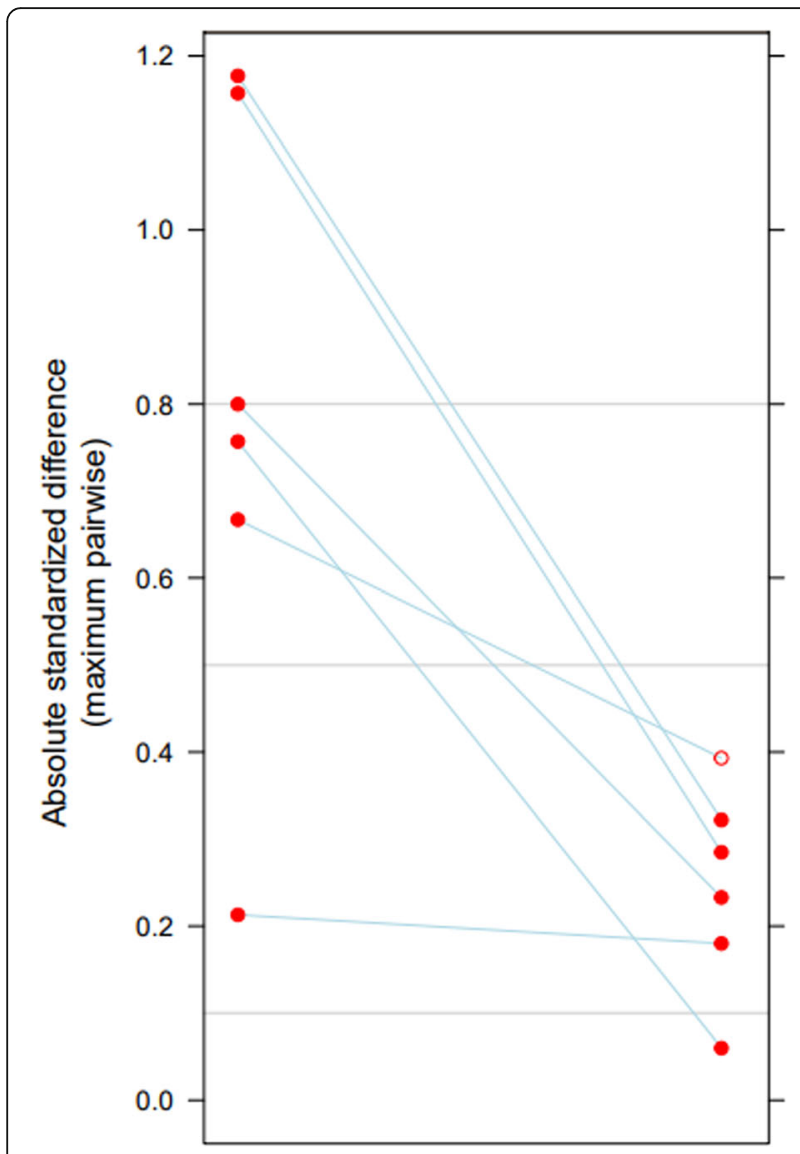

Fig. 1 Absolute standardized mean difference for all covariates in before and after propensity score weighting. Right indicates the absolute standardized mean difference before propensity score weighting, and left indicates the absolute standardized mean difference after applying propensity score weighting. Solid circle indicates statistically significant difference; hollow circle indicates statistically insignificant difference

standardized differences in the covariates included in the estimation had decreased to below 0.4 .

This study applied regression with estimated propensity score weights to examine each policy variable's association with medical utilization and out-of-pocket spending. Poisson and negative binomial models were developed for variables consisting of counts with nonnegative integer values. The negative binomial model is considered a more general model when the assumption of equi-dispersion in the Poisson basic model is not met, by including a random term that reflects the unexplained part in subject differences [34]. To accommodate the overdispersed count nature of outcome variables, this study applied a negative binomial model for outpatient use. The study used a zero-inflated Poisson model (ZIP) for hospital visits and a zero-inflated negative binomial (ZINB) model for hospitalized days and hospitalized days per visit to accommodate unique zero excessive count data structures [35]. Using the ZINB model is more appropriate for zero excessive count data when an assumption of equi-dispersion is not met. However, due to the distribution of hospital visits where zero visits account for $86.15 \%(n=9,679)$ of all respondents and one visit accounts for $77.57 \%(n=1207)$ of the respondents who visited the hospital at least once, the convergence needed to apply the ZINB model could not be met.

Because the out-of-pocket spending data is skewed to the right and was not normally distributed, a generalized linear model (GLM) with a log-link function using a gamma distribution was applied, which is the most suitable option for cost data analysis analyzing both mean and variance functions and adjusting the right-skewed distribution of cost data [36, 37]. The gamma distribution is undefined for values of ' 0 ', so an offset of 0.00001 was added to each out-of-pocket spending value in consideration of the users who had no out-of-pocket spending [38].

The occurrence of catastrophic health expenditures was modeled by applying binomial logistic regression to estimate each group's risk ratio and risk difference. All statistical analyses were performed using Stata ver. 16 (StataCorp, College Station, Texas, USA) and R 4.0.5. This study protocol was approved by the Institutional Review Board of Seoul National University (IRB No. E2010/001-004).

\section{Results}

\section{Demographic characteristics}

Various demographic and socioeconomic characteristics, health status, and occupation status among the three study groups were compared (Table 1). Medical Aid beneficiaries and the near-poor group were found to show similar health and socioeconomic status. However, the near-poor group tends to be more economically active than Medical Aid beneficiaries. The Medical Aid beneficiaries and the near-poor and were substantially older compared to the above-poverty-line group (66.21 versus 72.27 versus 50.27 ).

\section{Differences in health utilization among study groups}

Both Medical Aid beneficiaries and the above-povertyline group had no significant difference in outpatient and inpatient utilization compared to the near-poor group (Table 2). Respondents who had the chronic disease were estimated to have $238 \%$ more outpatient visits, $36 \%$ less chance of having no hospitalized days, and $50 \%$ more hospitalized days in all three groups. Respondents who reported having poor health were estimated to have $53 \%$ more outpatient visits and $36 \%$ less chance of zero hospitalized days, $50 \%$ more hospitalized 
Table 1 Demographic characteristics of the study population

\begin{tabular}{|c|c|c|c|c|c|c|c|c|}
\hline & \multicolumn{2}{|c|}{ Medical Aid beneficiaries } & \multicolumn{2}{|c|}{ Near-poor group } & \multicolumn{2}{|c|}{$\begin{array}{l}\text { Above-poverty-line } \\
\text { group }\end{array}$} & \multicolumn{2}{|l|}{ Total } \\
\hline & Frequency & $\begin{array}{l}\text { Relative } \\
\text { frequency } \\
(\%)\end{array}$ & Frequency & $\begin{array}{l}\text { Relative } \\
\text { frequency } \\
\text { (\%) }\end{array}$ & Frequency & $\begin{array}{l}\text { Relative } \\
\text { frequency } \\
\text { (\%) }\end{array}$ & Frequency & $\begin{array}{l}\text { Relative } \\
\text { frequency } \\
\text { (\%) }\end{array}$ \\
\hline $\mathbf{N}$ & 616 & 5.48 & 2,153 & 19.16 & 8,466 & 75.35 & 11,235 & \\
\hline \multicolumn{9}{|l|}{ Categorical variables } \\
\hline Female & 384 & 62.34 & 1,394 & 64.75 & 4,588 & 54.19 & 6,366 & 56.66 \\
\hline Married & 164 & 26.62 & 1,150 & 53.41 & 5,554 & 65.60 & 6,868 & 61.13 \\
\hline \multicolumn{9}{|l|}{ Education } \\
\hline eno diploma & 110 & 17.86 & 493 & 22.90 & 245 & 2.89 & 848 & 7.55 \\
\hline $\begin{array}{l}\text { ebelow high school } \\
\text { diploma }\end{array}$ & 328 & 53.25 & 1,221 & 56.71 & 2,021 & 23.87 & 3,570 & 31.78 \\
\hline ehigh school diploma & 129 & 20.94 & 303 & 14.07 & 2,665 & 31.48 & 3,097 & 27.57 \\
\hline $\begin{array}{l}\text { eabove high school } \\
\text { diploma }\end{array}$ & 49 & 7.95 & 136 & 6.32 & 3,535 & 41.76 & 3,720 & 33.11 \\
\hline \multicolumn{9}{|l|}{ Occupation } \\
\hline$\in$ permanent employee & 2 & 0.32 & 15 & 0.70 & 2,319 & 27.39 & 2,336 & 20.79 \\
\hline etemporary employee & 52 & 8.44 & 309 & 14.35 & 1,891 & 22.34 & 2,252 & 20.04 \\
\hline $\begin{array}{l}\in \text { employer, self-employed, } \\
\text { unpaid family worker }\end{array}$ & 11 & 1.79 & 302 & 14.03 & 1,161 & 13.71 & 1,474 & 13.12 \\
\hline $\begin{array}{l}\in \text { unemployed, } \\
\text { economically inactive }\end{array}$ & 551 & 89.54 & 1,527 & 70.92 & 3,095 & 36.56 & 5,173 & 46.04 \\
\hline Reporting bad health & 358 & 58.12 & 1,025 & 47.61 & 1,227 & 14.49 & 2,610 & 23.23 \\
\hline Chronic disease & 527 & 85.55 & 1,820 & 84.53 & 3,971 & 46.91 & 6,318 & 56.23 \\
\hline Disabled & 115 & 18.67 & 170 & 7.90 & 265 & 3.13 & 550 & 4.90 \\
\hline $\begin{array}{l}\text { Private insurance } \\
\text { subscription }\end{array}$ & 123 & 19.97 & 468 & 21.74 & 6,499 & 76.77 & 7,090 & 63.11 \\
\hline Depression & 276 & 44.81 & 649 & 30.14 & 782 & 9.24 & 1,707 & 15.19 \\
\hline \multicolumn{9}{|l|}{ Continuous variables } \\
\hline Age & $\begin{array}{l}66.21 \\
\text { (mean) }\end{array}$ & 16.60 (SD) & $\begin{array}{l}72.27 \\
\text { (mean) }\end{array}$ & 13.02 (SD) & $\begin{array}{l}50.27 \\
\text { (mean) }\end{array}$ & 17.65 (SD) & $\begin{array}{l}55.30 \\
\text { (mean) }\end{array}$ & $19.02(S D)$ \\
\hline $\begin{array}{l}\text { Monthly income (one } \\
\text { million won) }\end{array}$ & $\begin{array}{l}0.92 \\
\text { (mean) }\end{array}$ & 0.31 (SD) & $\begin{array}{l}0.81 \\
\text { (mean) }\end{array}$ & 0.53 (SD) & $\begin{array}{l}3.13 \\
\text { (mean) }\end{array}$ & 2.11 (SD) & $\begin{array}{l}2.56 \\
\text { (mean) }\end{array}$ & 2.09 (SD) \\
\hline
\end{tabular}

days, and $78 \%$ more hospitalized days per visit compared to those who did not report poor health.

Differences in out-of-pocket spending and chance of experiencing catastrophic health expenditure among the study groups

For out-of-pocket spending, the Medical Aid beneficiaries showed $66 \%$ less out-of-pocket spending, but the above-poverty group incurred $30 \%$ more out-of-pocket spending compared to the near-poor group (Table 3). In terms of the chance of experiencing catastrophic health expenditures, both Medical Aid beneficiaries and the above-poverty group were estimated to have a significantly less chance of experiencing catastrophic health expenditures at all thresholds compared to the nearpoor group.

Predicted value of health service utilization and out-ofpocket spending and likelihood of experiencing catastrophic health expenditure among study groups The predicted values of health service utilization were in ascending order of Medical Aid beneficiaries, the nearpoor, and the above-poverty line group (Table 4). For inpatient services, all three variables were also in ascending order of the near-poor, Medical Aid beneficiaries, and the above-poverty line group. The predicted value of out-of-pocket spending rose from the above-poverty line group to the near-poor group to the Medical Aid beneficiaries group. The likelihood of incurring catastrophic 
Table 2 Medical utilization among study groups

\begin{tabular}{|c|c|c|c|c|c|c|c|c|c|c|c|c|c|c|}
\hline & \multirow{2}{*}{\multicolumn{2}{|c|}{$\begin{array}{l}\text { Outpatient } \\
\text { visits } \\
\text { Negative } \\
\text { binominal }\end{array}$}} & \multicolumn{4}{|c|}{ Hospital visits } & \multicolumn{4}{|c|}{ Hospitalized days } & \multicolumn{4}{|c|}{$\begin{array}{l}\text { Hospitalized days per } \\
\text { visit }\end{array}$} \\
\hline & & & \multicolumn{2}{|c|}{ Poisson } & \multicolumn{2}{|l|}{ Logit } & \multicolumn{2}{|c|}{$\begin{array}{l}\text { Negative } \\
\text { binominal }\end{array}$} & \multicolumn{2}{|l|}{ Logit } & \multicolumn{2}{|c|}{$\begin{array}{l}\text { Negative } \\
\text { binominal }\end{array}$} & \multicolumn{2}{|l|}{ Logit } \\
\hline & $\beta$ & SE & $\beta$ & SE & $\beta$ & SE & $\beta$ & SE & $\beta$ & SE & $\beta$ & SE & $\beta$ & SE \\
\hline \multicolumn{15}{|l|}{ Study group } \\
\hline$\in$ Near-poor & - & - & - & - & - & - & - & - & - & - & - & - & - & - \\
\hline$\in$ Medical Aid & $0.20^{*}$ & 0.11 & 0.15 & 0.73 & 0.95 & 2.23 & -0.26 & 0.16 & $0.42^{*}$ & 0.23 & -0.17 & 0.16 & $0.43^{*}$ & 0.23 \\
\hline$\in$ Above-poverty & -0.03 & 0.08 & 0.18 & 1.02 & 0.41 & 2.99 & -0.15 & 0.12 & -0.01 & 0.18 & -0.15 & 0.12 & -0.02 & 0.18 \\
\hline Female & $0.30^{* * *}$ & 0.08 & -0.34 & 0.48 & -0.60 & 1.26 & $-0.19^{*}$ & 0.12 & -0.02 & 0.20 & $-0.22^{*}$ & 0.12 & -0.02 & 0.20 \\
\hline Age & $0.02^{* * *}$ & 0.00 & $-0.02^{* *}$ & 0.01 & $-0.04^{* *}$ & 0.02 & 0.01 & 0.01 & 0.00 & 0.01 & $0.02^{* * *}$ & 0.01 & 0.00 & 0.01 \\
\hline Married & 0.03 & 0.07 & -0.36 & 0.60 & -0.07 & 1.84 & $-0.21^{*}$ & 0.13 & $0.32^{*}$ & 0.19 & -0.18 & 0.12 & $0.32^{*}$ & 0.19 \\
\hline \multicolumn{15}{|l|}{ Education } \\
\hline eno diploma & - & - & - & - & - & - & - & - & - & - & - & - & - & - \\
\hline ebelow high school diploma & 0.03 & 0.07 & 0.29 & 0.31 & 0.06 & 0.63 & -0.06 & 0.15 & -0.17 & 0.16 & -0.16 & 0.16 & -0.18 & 0.16 \\
\hline ehigh school diploma & 0.00 & 0.12 & -0.06 & 0.33 & -0.78 & 0.68 & -0.07 & 0.23 & -0.23 & 0.26 & -0.19 & 0.22 & -0.24 & 0.26 \\
\hline eabove high school diploma & -0.04 & 0.14 & -0.40 & 0.42 & $-1.82^{*}$ & 1.09 & -0.22 & 0.29 & -0.33 & 0.25 & -0.22 & 0.27 & -0.32 & 0.25 \\
\hline \multicolumn{15}{|l|}{ Occupation } \\
\hline$\in$ permanent employee & - & - & - & - & - & - & - & - & - & - & - & - & - & - \\
\hline etemporary employee & $-0.36^{*}$ & 0.19 & -1.06 & 1.31 & -0.64 & 2.52 & $-0.68^{* *}$ & 0.32 & $0.77^{*}$ & 0.47 & $-0.75^{* *}$ & 0.34 & 0.75 & 0.47 \\
\hline $\begin{array}{l}\in \text { employer, self-employed, unpaid family } \\
\text { worker }\end{array}$ & -0.30 & 0.19 & -0.71 & 3.56 & -1.37 & 10.44 & $-0.51^{*}$ & 0.31 & 0.27 & 0.48 & $-0.65^{* *}$ & 0.34 & 0.25 & 0.48 \\
\hline$\in$ unemployed, economically inactive & -0.26 & 0.18 & -0.07 & 1.06 & -0.54 & 1.92 & -0.27 & 0.30 & -0.01 & 0.44 & -0.45 & 0.33 & -0.04 & 0.44 \\
\hline $\begin{array}{l}\text { Monthly income (increase of one million } \\
\text { won) }\end{array}$ & -0.01 & 0.02 & $-0.07^{* *}$ & -0.03 & 0.03 & 0.06 & -0.02 & 0.03 & 0.09 & 0.06 & -0.02 & 0.02 & 0.09 & 0.06 \\
\hline Self-reporting poor health & $0.43^{* * *}$ & 0.06 & 1.09 & 1.47 & -0.32 & 3.28 & $0.69^{* * *}$ & 0.13 & $-1.21^{* * *}$ & 0.19 & $0.58^{* * *}$ & 0.13 & $-1.22^{* * *}$ & 0.19 \\
\hline Chronic disease & $1.22^{* * *}$ & 0.08 & 0.90 & 1.12 & 0.80 & 3.48 & $0.41^{* *}$ & 0.18 & $-0.46^{* *}$ & 0.21 & 0.30 & 0.19 & $-0.47^{* *}$ & 0.21 \\
\hline Disabled & 0.00 & 0.07 & -0.10 & 0.33 & -0.10 & 0.50 & 0.27 & 0.21 & 0.18 & 0.18 & 0.08 & 0.18 & 0.17 & 0.18 \\
\hline Private insurance subscription & 0.12 & 0.07 & -0.22 & 1.01 & -1.05 & 1.98 & 0.02 & 0.16 & $-0.31^{* *}$ & 0.14 & 0.10 & 0.14 & $-0.30^{* *}$ & 0.14 \\
\hline Depression & $0.21^{* * *}$ & 0.08 & 0.59 & 1.58 & 0.54 & 3.64 & $0.33^{* *}$ & 0.14 & -0.17 & 0.18 & 0.16 & 0.13 & -0.18 & 0.18 \\
\hline
\end{tabular}

health expenditures was in the ascending order of the near-poor, Medical Aid recipients, and the abovepoverty line group at all four thresholds.

\section{Discussion}

This study found that the near-poor group was the most vulnerable group among the South Korean population in terms of their greater out-of-pocket spending and higher chance of incurring catastrophic health expenditures. There were no significant differences in medical utilization between the near-poor and either Medical Aid beneficiaries or the above-poverty group after controlling for potential bias. In addition, the near-poor were found to incur more out-of-pocket spending than Medical Aid beneficiaries and to have a significantly higher chance of experiencing catastrophic health expenditures at all thresholds compared to the two other groups. These results demonstrate that the near-poor group could be considered the most vulnerable population based on medical service utilization and out-ofpocket spending. This assumption is in agreement with the results reported by several other studies. Medical Aid beneficiaries were found to use more inpatient and outpatient services, incurred less out-of-pocket spending, and had a lower chance of experiencing catastrophic health expenditures compared to NHI members [39]. A study that defined the near poor as people not enrolled in Medical Aid but with an income less than $120 \%$ of the minimum cost of living found that Medical Aid beneficiaries experienced significantly lower health care costs and proportion of out-of-pocket spending to income compared to the poor not enrolled in Medical Aid [11]. Studies conducted in the US showed that the most important factor in determining whether people are obtaining sufficient medical service is being uninsured 
Table 3 Out-of-pocket (OOP) spending and occurrence of catastrophic health expenditures (CHE) among study groups

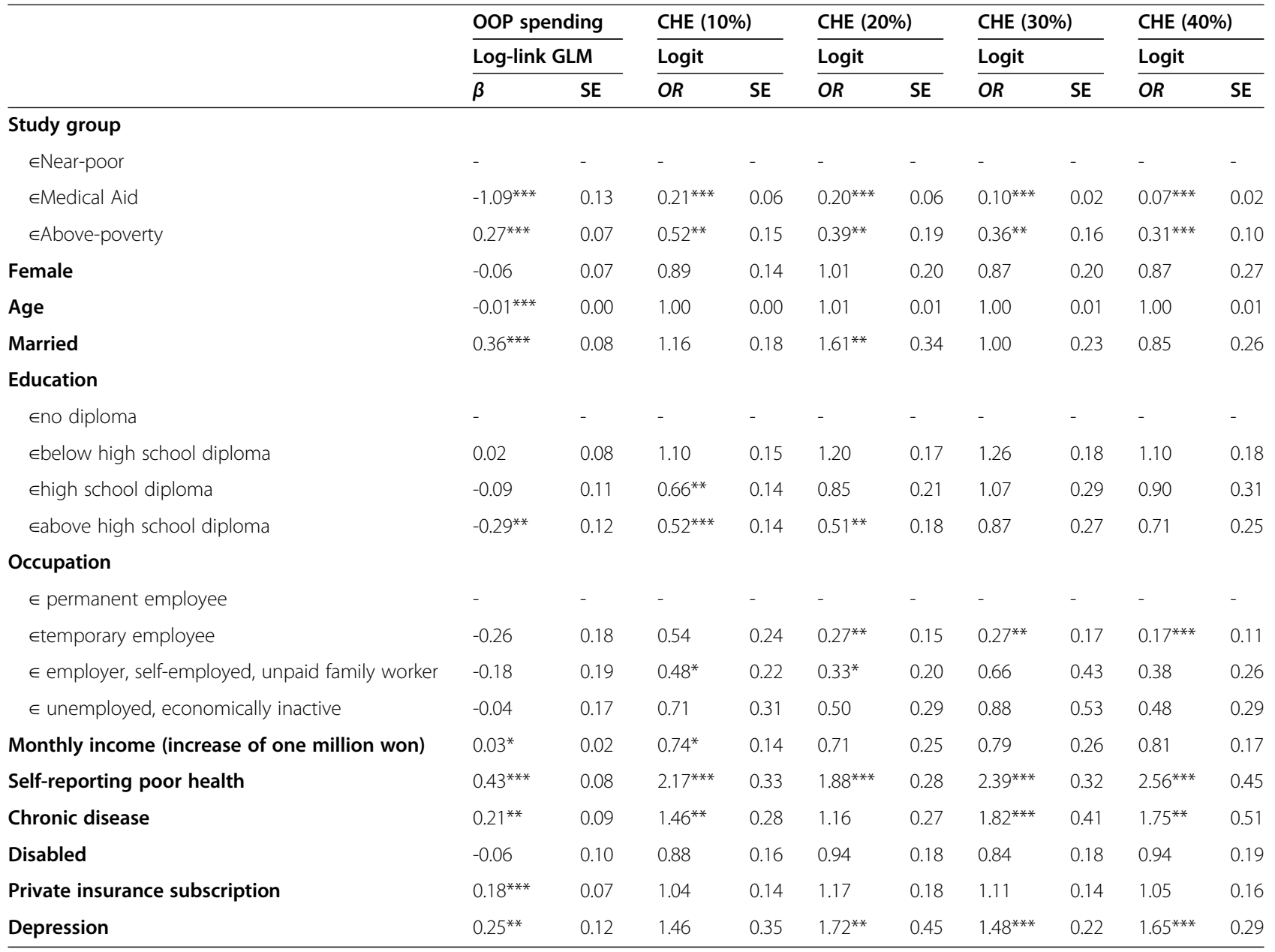

*** $p<0.001 * * p<0.05 * p<0.1$

with low income [40, 41]. Studies on the effect of the US Medicaid program among the poor and near-poor have shown that the uninsured experienced difficulties obtaining medical care and that the expansion of US Medicaid lowered out-of-pocket costs [42-44]. However, contrary to previous findings, this study indicates that medical utilization did not differ among the three groups. This might demonstrate the significant association of the expansion of the catastrophic health expenditure support program in 2018 and the overall $\mathrm{NHI}$

Table 4 Predicted value of health service utilization and out-of-pocket spending, chance of occurrence of catastrophic health expenditure

\begin{tabular}{|c|c|c|c|c|c|c|c|c|c|c|}
\hline & \multicolumn{2}{|c|}{ Outpatient visits } & \multicolumn{2}{|c|}{ Hospital visits } & \multicolumn{2}{|c|}{ Hospitalized days } & \multicolumn{4}{|c|}{ Hospitalized days per visit } \\
\hline & Mean & SD & Mean & SD & Mean & SD & Mean & SD & & \\
\hline Medical Aid & 36.16 & 18.38 & 0.33 & 0.24 & 5.63 & 4.67 & 3.99 & 3.12 & & \\
\hline Near-poor & 29.82 & 14.66 & 0.34 & 0.27 & 6.97 & 6.74 & 4.98 & 4.39 & & \\
\hline \multirow[t]{3}{*}{ Above-poverty } & 13.71 & 11.81 & 0.15 & 0.16 & 1.92 & 3.16 & 1.52 & 2.16 & & \\
\hline & \multicolumn{2}{|c|}{ OOP spending } & \multicolumn{2}{|c|}{ CHE (10\%) } & \multicolumn{2}{|c|}{ CHE (20\%) } & \multicolumn{2}{|c|}{ CHE (30\%) } & \multicolumn{2}{|c|}{ CHE (40\%) } \\
\hline & Mean & SD & Mean & SD & Mean & SD & Mean & SD & Mean & SD \\
\hline Medical Aid & 80.04 & 28.91 & 0.32 & 0.13 & 0.16 & 0.08 & 0.06 & 0.03 & 0.02 & 0.01 \\
\hline Near-poor & 226.16 & 84.77 & 0.65 & 0.14 & 0.46 & 0.16 & 0.33 & 0.15 & 0.22 & 0.12 \\
\hline Above-poverty & 299.01 & 96.43 & 0.23 & 0.14 & 0.10 & 0.08 & 0.05 & 0.05 & 0.02 & 0.03 \\
\hline
\end{tabular}


coverage expansion that has been taking place since 2017 on medical utilization. Furthermore, the current administration implemented an NHI coverage expansion in 2017 by alleviating the uncovered services cost burden [45]. Because previous research was based on data from before 2016, the findings do not reflect these recently implemented policies affecting the medical utilization of the near-poor. Further study is needed to examine the outcome of these latest policy changes on medical utilization among the near-poor in South Korea.

Although medical utilization showed no significant difference for the above-poverty and the near-poor groups, out-of-pocket spending in the above-poverty group was greater compared to among the near-poor. There is a chance that the recently implemented out-of-pocket spending threshold restricting out-of-pocket spending to $10 \%$ of annual income for the bottom $50 \%$ income group has influenced the out-of-pocket spending of the near-poor in terms of association [45]. Also, South Korea's NHI has been criticized for insufficient coverage, meaning many medical services are perceived as going uncovered. Due to economic difficulties, the near-poor have a limited capacity to use uncovered services compared to the non-poor, resulting in uncovered health care utilization and out-of-pocket spending being skewed toward the better-off [46-48]. At the same time, the better-off are more likely to be subscribers to private health insurance, impacting their out-of-pocket costs [49].

The presence of chronic disease was significantly associated with greater outpatient and inpatient use among the three study groups. Chronic disease has been confirmed in several studies as a significant factor in determining outpatient service use, such as in terms of the number of outpatient visits [50]. Because the average age of this study population is high, the presence of chronic disease is likely associated with higher inpatient use due to a lack of proper self-management [51, 52]. Additional focus is required on chronic disease prevention by empowering the population through strengthened education. Self-management programs must be supported in order to mitigate hospitalization due to chronic disease. In addition, perceived negative health status was associated with greater outpatient and inpatient use. Perceived negative health status can lead to poor physical health and greater social isolation [53]. Thus, self-evaluated health status should be considered in the development of health promotion programs for both Medical Aid beneficiaries NHI members.

South Korea has regularly implemented expansions of NHI coverage and pursued the reduction of copayments and the implementation of support programs for catastrophic health expenditures among the poor population to ensure proper health care use and prevent impoverishment due to health care costs. Despite these efforts, several studies, including this study, have demonstrated that the near-poor population remains unprotected from the occurrence of catastrophic health expenditures. Moreover, previous studies have found that the near-poor population experiences higher unmet needs compared to Medical Aid beneficiaries [54]. An expansion of Medical Aid could be considered an alternative for alleviating this burden and ensuring the provision of essential health services among the nearpoor. Lee (2020) [15] found that people who shifted from NHI to Medical Aid raised their number of outpatient visits without increasing out-of-pocket spending. A more focused policy for populations in this blind spot within the health care system, including their perceived health status and chronic disease, is required to ensure the provision of essential health services to the nearpoor group.

This study has certain limitations and strengths. The findings may not be generalizable to other countries with divergent medical utilization and out-of-pocket spending programs. Second, the issue of supply-induced demand among Medical Aid beneficiaries could not be resolved. Third, although propensity score weighting was used to adjust for potential bias, several factors that could influence medical utilization and out-of-pocket spending could not be examined due to a lack of data. Finally, given the limits of this data, the use of uncovered medical services could not be identified because medical services were not categorized as covered or uncovered. Because several high-quality medical services offered in South Korea are not covered by either Medical Aid or $\mathrm{NHI}$, the quality of medical service that respondents experienced could not be verified. Future research should examine the various factors that may influence medical utilization and out-of-pocket spending, including variables such as unmet needs, health service quality, and service accessibility.

The strengths of this study include its analysis of socioeconomic and health-related factors and the use of different statistical methods to accommodate the unique characteristics of outcome variables and minimize potential bias. In addition the medical utilization and outof-pocket spending of an above-poverty-line group not included in previous studies were examined.

\section{Conclusions}

This study found that the near-poor population showed no significant difference in medical utilization compared to the Medical Aid and above-poverty-line groups, but they incurred greater out-of-pocket spending and were exposed to a higher likelihood of incurring catastrophic health expenditures. This result indicates that the nearpoor group is the most vulnerable within South Korea's 
population. Health policy needs to take this vulnerability of the near-poor population into account along with several factors, such as chronic disease and perceived health status, that is associated with medical use and cost in order to ensure essential services and provide protection from impoverishment by health care costs.

\section{Abbreviations \\ NHI: National Health Insurance; CESD: Center for Epidemiological Studies- Depression; GBM: Generalized boosted model; ZIP: Zero-inflated Poisson; ZINB: Zero-inflated negative binomial; GLM: Generalized linear model}

\section{Acknowledgements}

I am very grateful to Professors Soonman Kwon and Wankyo Chung for their help with the interpretation of the data, and to Professors Juhyun Park and Taejin Lee for their help with the methods.

\section{Authors' contributions}

SP designed this study, reviewed the literature, performed statistical analysis, interpreted the data, drafted, revised, completed the study. The authors read and approved the final manuscript.

\section{Funding}

There was no external funding for this research.

\section{Availability of data and materials}

The data set analyzed for the current study is available as part of the Korea Welfare Panel Study, [https://www.koweps.re.kr/].

\section{Declarations}

\section{Ethics approval and consent to participate}

This study protocol was approved by the Institutional Review Board of Seoul National University (IRB No. E2010/001-004). The data, 2018 Korea Welfare Panel Study, which this study relies upon are openly published, so this study did not collect inform consent from the participants. Prior to the analysis, respondents information was fully anonymized. No additional administrative permission is required to access and use the datasets used in this study.

\section{Consent to publication}

Not applicable.

\section{Competing interests}

The author declares that he has no competing interests.

Received: 1 December 2020 Accepted: 3 August 2021

Published online: 28 August 2021

\section{References}

1. World Health Organization. Regional Office for the Western P. Republic of Korea health system review. Manila: WHO Regional Office for the Western Pacific; 2015.

2. Hansen $\mathrm{AH}$, Halvorsen $\mathrm{PA}$, Ringberg U, Førde $\mathrm{OH}$. Socio-economic inequalities in health care utilisation in Norway: a population based crosssectional survey. BMC Health Serv Res. 2012;12(1):336.

3. Saeed BLM, Aidoo EN, Nsowah-Nuamah NN, Yawson AE, Zhao X. Socioeconomic inequalities and healthcare utilization in Ghana. Int I Bus Soc Res. 2013;3(1):54-63

4. Koo J, Yoo S, Lee H, Son T. A comparison of the recognition and satisfaction for health care service between internal customer and external customer. Health Policy Management. 2000;10(1):111-25.

5. Lee H. Healthcare utilization and out-of-pocket spending of Medical Aids recipients in South Korea: a propensity score matching with National Health Insurance participants. Korean Health Econ Rev. 2016;22(2):29-49.

6. Yu W. Problems and improvement measures of recent changes in medical benefits joining. Welf Trends. 2008;120:53-63.

7. Lee H, Park H, Lee J. Statistical Yearbook of Poverty 2019. Osong: Korea Institute for Health And Social Affairs; 2019. p. 112.
8. Shon B. The Family Support Obligation Rule in the National Basic Livelihood Security System: Its Limitation and Way Forward. Health: KIHASA; 2019. p. $32-45$.

9. Kim J. Comparative Study on Public Health Care Coverage for Low Income Bracket -Comparison between Medical Benefits and Medicaid-. Korean Comp Gov Rev. 2013;17(3):195-220.

10. OECD. Society at a Glance 2019: OECD Social Indicators. Paris: OECD Publishing; 2019.

11. Choi J, Park E, Chun S, Han K, Han E, Kim T. Health care utilization and costs among medical-aid enrollees, the poor not enrolled in medical-aid, and the near poor in South Korea. Int J Equity Health. 2015;14:128.

12. Kim J. Equity in Health Levels and Health Care Utilization of Elderly People in Korea. Soc Sci Res Rev. 2011;27(2):65-87.

13. Kwon S. Thirty years of national health insurance in South Korea: lessons for achieving universal health care coverage. Health Policy Plan. 2009;24(1):6371.

14. Kim J, Lee K, Yoo K, Park E. The differences in health care utilization between Medical Aid and health insurance: a longitudinal study using propensity score matching. PLoS One. 2015;10(3):e0119939.

15. Lee D, Jang J, Choi D, Jang S, Park E. The effect of shifting medical coverage from National Health Insurance to Medical Aid type I and type II on health care utilization and out-of-pocket spending in South Korea. BMC Health Serv Res. 2020;20(1):979.

16. Choi H. Catastrophic health expenditure and Unmet needs of low-income households depending on the types of Healthcare system [master's thesis]. Seoul: Seoul National University; 2017

17. Angier H, Hoopes M, Gold R, Bailey SR, Cottrell EK, Heintzman J, et al. An early look at rates of uninsured safety net clinic visits after the Affordable Care Act. Annals of Family Medicine. 2015;13(1):10-6.

18. Cole MB, Galárraga O, Wilson IB, Wright B, Trivedi AN. At Federally Funded Health Centers, Medicaid Expansion Was Associated With Improved Quality Of Care. Health Aff. 2017;36(1):40-8.

19. Heintzman J, Bailey SR, DeVoe J, Cowburn S, Kapka T, Duong TV, et al. In Low-Income Latino Patients, Post-Affordable Care Act Insurance Disparities May Be Reduced Even More than Broader National Estimates: Evidence from Oregon. J Racial Ethnic Health Disparities. 2017;4(3):329-36.

20. Sommers BD, Blendon RJ, Orav EJ, Epstein AM. Changes in Utilization and Health Among Low-Income Adults After Medicaid Expansion or Expanded Private Insurance. JAMA Int Med. 2016;176(10):1501-9.

21. Carrin G, James C. Social Health Insurance: Key Factors Affecting the Transition Towards Universal Coverage. Int Soc Secur Rev. 2005;58:45-64.

22. Health Insurance Review and Assessment Service, National Health Insurance Service. Medical Aid Statistics 2018. Wonju: HIRA, NHIS; 2019.

23. Enforcement decree of the National Health Insurance Act 2015 art. 19 (S. Kor).

24. Oh J, Ko Y, Baer Alley A, Kwon S. Participation of the Lay Public in DecisionMaking for Benefit Coverage of National Health Insurance in South Korea. Health Syst Reform. 2015;1 (1):62-71.

25. Ministry of Health and Welfare. 2018 Catastrophic health expenditure support program guidance. Sejong: Ministry of Health and Welfare; 2018. p. 186.

26. Park E. Moon Jae-in Government's Plan for Benefit Expansion in National Health Insurance. Health Policy Mange. 2017;27(3):191-8.

27. Ryu J. Assistance Programs for Low Income Families in Korea and Policy Suggestions. HealthWelfare Issue Focus. 2014;288:1-8.

28. Wyszewianski L. Financially Catastrophic and High-Cost Cases: Definitions, Distinctions, and Their Implications for Policy Formulation. Inquiry. 1986; 23(4):382-94.

29. Jun J, Yee N, Depression. Its Concurrent Chronic Illnesses, and Related Health Service Use in the Korea Welfare Panel Data. Health Welfare Policy Forum. 2015;219:75-84.

30. Rubin DB. Estimating causal effects of treatments in randomized and nonrandomized studies. J Educ Psychol. 1974;66(5):688-701.

31. McCaffrey DF, Griffin BA, Almirall D, Slaughter ME, Ramchand R, Burgette LF. A tutorial on propensity score estimation for multiple treatments using generalized boosted models. Stat Med. 2013;32(19):3388-414.

32. Cefalu M, Buenaventura M. Propensity Scores for Multiple Treatments: A Tutorial on the MNPS Command for Stata Users. Santa Monica(CA): RAND Corporation; 2017

33. Wyss R, Girman CJ, LoCasale RJ, Brookhart AM, Stürmer T. Variable selection for propensity score models when estimating treatment effects on multiple outcomes: a simulation study. Pharmacoepidemiol Drug Saf. 2013;22(1):7785 
34. Cameron AC, Trivedi PK. Regression Analysis of Count Data. 2nd ed. Cambridge: Cambridge University Press; 2013.

35. Solé-Auró A, Guillén M, Crimmins EM. Health care usage among immigrants and native-born elderly populations in eleven European countries: results from SHARE. Eur J Health Econ. 2012;13(6):741-54.

36. Hill S, Miller $\mathrm{G}$. Health expenditure estimation and functional form: applications of the generalized Gamma and extended estimating equations models. Health Econ. 2009;19:608-27.

37. Mihaylova B, Briggs A, O'Hagan A, Thompson SG. Review of statistical methods for analysing healthcare resources and costs. Health Econ. 2011; 20(8):897-916.

38. Liao $E$, Leahy $M$, Cummins $G$. The costs of nonsedating antihistamine therapy for allergic rhinitis in managed care: an updated analysis. The American Journal of Managed Care. 2001;7(15 Suppl):459-68.

39. Kong N, Kim D. Factors influencing health care use by health insurance subscribers and medical aid beneficiaries: a study based on data from the Korea welfare panel study database. BMC Public Health. 2020;20(1):1133.

40. Sibley LM, Glazier RH. Reasons for self-reported unmet healthcare needs in Canada: a population-based provincial comparison. Healthc Policy. 2009;5(1): 87-101.

41. Pagán JA, Pauly MV. Community-level uninsurance and the unmet medical needs of insured and uninsured adults. Health Serv Res. 2006;41(3 Pt 1):788803.

42. Mulcahy AW, Eibner C, Finegold K. Gaining Coverage Through Medicaid Or Private Insurance Increased Prescription Use And Lowered Out-Of-Pocket Spending. Health Aff. 2016;35(9):1725-33.

43. Cunningham PJ, Kemper P. Ability to Obtain Medical Care for the UninsuredHow Much Does It Vary Across Communities? JAMA. 1998; 280(10):921-7.

44. Baicker $\mathrm{K}$, Finkelstein $\mathrm{A}$. The effects of Medicaid coverage-learning from the Oregon experiment. N Engl J Med. 2011;365(8):683-5.

45. Kang H. Issues and Policy Options for Moon Jae-in Care. Health and Welfare Policy Forum: KIHASA; 2018. p. 23-37.

46. O'Donnell O, van Doorslaer E, Rannan-Eliya RP, Somanathan A, Adhikari SR, Akkazieva B, et al. Who pays for health care in Asia? J Health Econ. 2008; 27(2):460-75.

47. Veugelers PJ, Yip AM. Socioeconomic disparities in health care use: Does universal coverage reduce inequalities in health? J Epidemiol Community Health. 2003;57(6):424.

48. James CD, Hanson K, McPake B, Balabanova D, Gwatkin D, Hopwood I, et al. To retain or remove user fees?: reflections on the current debate in lowand middle-income countries. Appl Health Econ Health Policy. 2006;5(3): 137-53.

49. Kim S, Kwon S. The effect of extension of benefit coverage for cancer patients on health care utilization across different income groups in South Korea. Int J Health Care Finance Econ. 2014;14(2):161-77.

50. Gotsadze G, Tang W, Shengelia N, Zoidze A. Determinants analysis of outpatient service utilisation in Georgia: can the approach help inform benefit package design? Health Res Policy Syst. 2017;15(1):36-

51. Nie JX, Wang L, Tracy CS, Moineddin R, Upshur RE. Health care service utilization among the elderly: findings from the Study to Understand the Chronic Condition Experience of the Elderly and the Disabled (SUCCEED project). J Eval Clin Pract. 2008;14(6):1044-9.

52. Vegda K, Nie JX, Wang L, Tracy CS, Moineddin R, Upshur RE. Trends in health services utilization, medication use, and health conditions among older adults: a 2-year retrospective chart review in a primary care practice. BMC Health Serv Res. 2009;9:217.

53. Gunzelmann T, Hinz A, Brähler E. Subjective health in older people. Psychosoc Med. 2006;3:Doc02-Doc.

54. Kim T. The current state and affecting factors of unmet medical needs in Medical Aids recipients and lower income group [master's thesis]. Seoul: Hanyang University; 2020.

\section{Publisher's Note}

Springer Nature remains neutral with regard to jurisdictional claims in published maps and institutional affiliations.

\section{Ready to submit your research? Choose BMC and benefit from}

- fast, convenient online submission

- thorough peer review by experienced researchers in your field

- rapid publication on acceptance

- support for research data, including large and complex data types

- gold Open Access which fosters wider collaboration and increased citations

- maximum visibility for your research: over $100 \mathrm{M}$ website views per year

At BMC, research is always in progress.

Learn more biomedcentral.com/submissions 